\title{
I \\ GESTÃO DA INFORMAÇÃO, GESTÃO DO CONHECIMENTO, CULTURA ORGANIZACIONAL E COMPETÊNCIA EM INFORMAÇÃO: O QUARTETO ESTRATÉGICO PARA A CONSTRUÇÃO E USO COMPETENTE DA MEMÓRIA ORGANIZACIONAL
}

\author{
Cristiana Aparecida Portero Yafushi \\ Doutoranda em Ciência da Informação pela Universidade Estadual Paulista \\ Júlio Mesquita Filho, Brasil. \\ E-mail: cristianayafushi@gmail.com \\ Maria Fabiana Izídio de Almeida \\ Doutoranda em Ciência da Informação pela Universidade Estadual Paulista \\ Júlio Mesquita Filho, Brasil. \\ E-mail: izidio1985@yahoo.com.br \\ Marcia Cristina de Carvalho Pazin Vitoriano \\ Doutora em História Social pela Universidade de São Paulo, Brasil. \\ Professora da Universidade Estadual Paulista Júlio Mesquita Filho, Brasil. \\ E-mail: marcia.pazin@unesp.br
}

\begin{abstract}
Resumo
Apresenta reflexões e questionamentos acerca da importância da Gestão da Informação, da Gestão do Conhecimento, da Cultura Organizacional e da Competência em Informação em relação à criação e uso competentes da Memória Organizacional, questionando a possibilidade de elaboração de diretrizes que norteiam a construção e o uso competente da Memória organizacional, a partir das ferramentas e elementos do quarteto estratégico organizacional. Trata-se de pesquisa de natureza qualitativa, descritiva e exploratória utilizando como procedimentos metodológicos a pesquisa bibliográfica sobre Gestão da Informação, Gestão do Conhecimento, Cultura Organizacional, Competência em Informação e Memória Organizacional, gerando como resultado a elaboração de um quadro teórico-conceitual com a contribuição estratégica dos temas abordados para a criação e a consolidação da Memória Organizacional no ambiente empresarial. Como resultado da integração dos temas, foram estabelecidas cinco diretrizes para a estruturação da Memória Organizacional de maneira coesa, ampliando as possibilidades de reutilização da informação estratégica pela organização ao longo do tempo, com resultados no crescimento, no aumento da lucratividade e na consolidação organizacional.
\end{abstract}

Palavras-chave: Cultura Organizacional. Gestão do Conhecimento. Gestão da Informação. Competência em Informação. Memória Organizacional.

\section{INFORMATION MANAGEMENT, KNOWLEDGE MANAGEMENT, ORGANIZATIONAL CULTURE AND INFORMATION SKILLS: THE STRATEGIC QUARTET FOR THE CONSTRUCTION AND COMPETENT USE OF ORGANIZATIONAL MEMORY}

\begin{abstract}
This research presents reflections and questions about the importance of Information Management, Knowledge Management, Organizational Culture and Information Literacy in relation to the competent creation and use of Organizational Memory. In this way, the following research problem is proposed: Is it possible, from the tools and elements of the organizational strategic quartet, to elaborate guidelines
\end{abstract}

Perspectivas em Gestão \& Conhecimento, João Pessoa, v. 9, n. 3, p. 4-20, set./dez. 2019. DOI: http://dx.doi.org/10.21714/2236-417X2019v9n3p4

http://periodicos.ufpb.br/ojs2/index.php/pgc. ISSN: 2236-417X. Publicação sob Licença (cc) EY-NC-ND 
that guide the construction and competent use of Organizational Memory? It is a qualitative, descriptive and exploratory research using as methodological procedures the bibliographic research on Information Management, Knowledge Management, Organizational Culture, Information Literacy and Organizational Memory, generating as a result the elaboration of a theoretical-conceptual framework with the strategic contribution of the themes addressed to the creation and consolidation of Organizational Memory in the business environment. As a result of the integration of the themes, five guidelines were established for the structuring of Organizational Memory in a cohesive way, increasing the possibilities of re-use of strategic information by the organization over time, with results in growth, increased profitability and organizational consolidation.

Keywords: Organizational Culture. Knowledge Management. Information Management. Information Literacy. Organizational Memory.

\section{INTRODUÇÃO}

$\mathrm{Na}$ sociedade contemporânea, as organizações buscam estratégias eficientes que gerem resultados positivos, competitividade, qualidade, redução de custos, lucratividade, maximização de seus processos e minimização dos seus dispêndios, além do reconhecimento da sociedade e a criação de oportunidades de exploração de novos mercados. A informação e o conhecimento produzidos no âmbito das organizações são elementos indispensáveis para o sucesso organizacional, porém gerenciá-los é um desafio constante.

A preservação da informação e do conhecimento produzidos dentro da organização ao longo do tempo configura-se como uma estratégia importante para ampliar a capacidade das organizações de, ao acumular repertório de atuação, utilizarem-no como instrumento de reflexão sobre sua atuação e fortalecerem a rede de criação de conhecimento da organização.

Ao processo de construção deste reportório informacional e de conhecimento, damos o nome de Memória Organizacional (MO), que configura o "[...] acervo de informação, conhecimento e práticas, agregados e retidos pela organização ao longo de sua existência, utilizados para o suporte às suas atividades [...] e para a preservação de seu capital intelectual [...]" (MENEZES, 2006, p. 31). Esse cenário impulsiona também a Gestão do Conhecimento.

Entendemos a MO como um processo complexo que envolve uma série de elementos articulados, tais como: a Gestão da Informação (GI), a Gestão do Conhecimento (GC), a Cultura Organizacional e a Competência em Informação (Colnfo), que podem ser propostos em conjunto, como um “Quarteto Estratégico" para a construção e uso competente da Memória Organizacional (MO), pois são ferramentas de gestão valiosas e promissoras que juntas e inter-relacionadas são norteadoras competentes, que agregam valor ao desempenho de processos e atividades organizacionais.

Nesse contexto, é necessário que exista uma cultura que proporcione ambiente adequado de compartilhamento, em que os colaboradores disponham de apoio e recursos para desenvolver suas competências, que estimule o aprendizado contínuo e possibilite mudanças individuais, coletivas e organizacionais. "A cultura organizacional passa a ser a mente da organização, a crença comum que se reflete nas tradições e nos hábitos, bem como em manifestações mais perceptíveis (histórias, símbolos, ou mesmo edifícios e produtos)" (ARRUDA, 2006, p. 18). A cultura é o elemento integrador por excelência, que possibilita a construção de um contexto propício ao compartilhamento e uso da informação.

Além disso, as organizações também necessitam se munir de profissionais competentes, que saibam utilizar-se de toda essa informação, conhecimento e de todos os benefícios que a cultura organizacional propicia. Esse profissional deverá ser competente em informação, colocando em prática suas "[...] habilidades para encontrar, avaliar, interpretar,

Perspectivas em Gestão \& Conhecimento, João Pessoa, v. 9, n. 3, p. 4-20, set./dez. 2019. 
criar e aplicar informação disponível na geração de novos conhecimentos" (BELLUZZO; KOBAYASHI; FERES, 2004, p. 95).

Entendemos que as organizações que fazem uso do quarteto estratégico (GI, GC, Cultura Organizacional e Colnfo) estarão contribuindo efetivamente para a construção e uso competente da memória organizacional, que abarca o reconhecimento, a classificação e utilização da trajetória organizacional para construção de novas estratégias, isso por meio de registros sistemáticos do cotidiano operacional organizacional. Neste âmbito, o presente artigo possui a seguinte questão como proposta de pesquisa: É possível, a partir das ferramentas e elementos do quarteto estratégico organizacional elaborar diretrizes que norteiam a construção e o uso competente da Memória Organizacional?

A presente pesquisa objetiva apresentar as reflexões e questionamentos acerca dos conceitos de GI, GC, Cultura Organizacional e Colnfo, em relação à criação e uso competente da memória organizacional. Sua justificativa consiste no fato de que todos esses elementos se inter-relacionam e podem ser utilizados como norteadores estratégicos nas tomadas de decisões nos ambientes organizacionais.

A presente pesquisa foi fundamentada com base teórica na pesquisa bibliográfica visando identificar diferentes abordagens de autores renomados e reconhecidos pela área, de modo a propiciar o exame de temas já tratados por outros autores, mas agora abordados sob novos enfoques que permitam conclusões inovadoras (MARCONI; LAKATOS, 2006).

Neste aspecto, almeja-se contribuir para as áreas da Administração, da Arquivologia e da Ciência da Informação, entre outras áreas afins, que contemplem os temas da Gestão da Informação (GI), Gestão do Conhecimento (GC), Cultura Organizacional, Competência em Informação (Colnfo) e Memória Organizacional (MO), por meio da elaboração de um quadro teórico-conceitual trazendo todo esse arcabouço teórico e sua inferências e inter-relações no ambiente organizacional.

\section{MEMÓRIA ORGANIZACIONAL}

Compreender a trajetória da organização, sem dúvida, permite conhecer seus principais desafios, erros, acertos, caminhos, dentre outros fatores do passado que permitirão decisões mais assertivas para o futuro. As organizações que passam a registrar, controlar e principalmente acessar sua história possuem um diferencial competitivo. Os estudos sobre a memória das organizações evoluíram a partir da compreensão de que é necessário construir ferramentas que sejam capazes de utilizar os fatos passados da organização e associá-los tanto a mecanismos de registro quanto às estratégias de representação, de modo a utilizar a memória como ferramenta de gestão.

O conceito de memória utilizado tem origem nas ciências humanas, Le Goff (1992, p. 423) define a memória, "como propriedade de conservar certas informações, remete-nos a um conjunto de funções psíquicas, graças às quais o homem pode atualizar impressões ou informações passadas, ou que ele representa como passadas". Neste aspecto, a memória está relacionada às lembranças, percepções, experiências práticas, vivenciadas e assimiladas de situações positivas e negativas, que são recuperadas em momento posterior para serem reutilizadas.

Assim como o indivíduo constrói essa memória para si e passa essa impressão individual aos outros, a organização também possui uma memória que é construída pelos seus membros organizacionais, pelas informações disponibilizadas, pelo conhecimento, pelos fluxos de informação e pelos instrumentos tecnológicos e comunicacionais utilizados e preservados ao longo do tempo.

Perspectivas em Gestão \& Conhecimento, João Pessoa, v. 9, n. 3, p. 4-20, set./dez. 2019. 
Podemos dividir a memória em dois conceitos diferentes e complementares. Um deles é a Memória Institucional (MI) que, num contexto de valor social do grupo, apresenta uma abordagem mais generalista, voltada às questões culturais e históricas da organização como um todo, muito utilizado pelo setor de marketing. O outro conceito abarca a Memória Organizacional, nesta perspectiva, Molina e Valentim (2015, p. 61-62) defendem que a Memória Organizacional (MO) é composta por conhecimentos que "[...] são explicitados e registrados em documentos que, por sua vez, podem ser divididos em tipos documentais".

Por seu caráter de registro, a MO é fundamental para que a organização alcance diferenciais competitivos, pois é geradora de conhecimento explícito, captado das mentes dos seus membros organizacionais, das atividades e processos realizados, das percepções, impressões, significados, valores, crenças e práticas corporativas disseminadas, assim como daqueles registros compilados, tratados, selecionados e transformados em conteúdo formal disponibilizados em manuais, normas, procedimentos, rotinas, tarefas, processos, documentos internos.

Para que isso ocorra, essas informações necessitam de tratamento adequado, análise, compreensão, reflexão inteligente e racional que proporcione ao usuário quando acessar essa informação, criar novos conhecimentos e gerar decisões estratégicas. Bighetti (2016) ressalta:

“O emprego estratégico dessa memória produzida em parceria e validada pelo afeto em ações de comunicação é capaz de legitimar as atitudes empresariais [...] criando para a organização diferenciais que a destaque perante seus concorrentes" (BIGHETTI, 2016, p. 36, grifo nosso).

Quando criada a partir da composição de diferentes elementos e ferramentas gerenciais da organização, a MO torna-se mais abrangente e é capaz de proporcionar a utilização do conhecimento explícito ao longo do tempo como insumo para a construção de conhecimento e reutilização da informação pregressa.

\subsection{Gestão da Informação e suas etapas}

A Era da Informação consolida-se a partir da década de 1980, como resultado da expansão da globalização e da Tecnologia da Informação e Comunicação (TIC) e das diversas mudanças nos ambientes competitivos organizacionais, que proporcionaram o crescimento das empresas e a abertura dos mercados para a exportação dos seus produtos. Santos (2014) corrobora, ao afirmar que esta foi uma fase de incertezas nos processos produtivos devido ao alto grau de imprevisibilidade do contexto econômico organizacional, refletindo na busca pelo controle e domínio da qualidade, da competitividade, da produtividade e na absorção de mais clientes diariamente.

Cabe distinguir o que de fato é dado, informação e conhecimento, conforme corroboram Davenport e Prusak (2003), ao declararem que, os dados são encontrados em dispositivos e podem ser transferidos aos indivíduos, setores, organizações em diferentes contextos. Já a informação, exige do indivíduo análise e requer sua inferência para dar significado; quanto ao conhecimento, exige reflexão e aprendizado frente à realidade vivenciada.

Do ponto de vista organizacional, a informação pode ser categorizada como orgânica ou não-orgânica, conforme abordam Rousseau e Couture (1998) e Lousada (2011). A informação orgânica é aquela produzida e acumulada no desempenho das funções organizacionais, está relacionada ao contexto interno organizacional e a seus fluxos de informação formais; recebe avaliação, tratamento e classificação, possui caráter sigiloso, confiável, tramita entre os setores e contribui para o alcance da missão, visão e objetivos organizacionais, além da preservação da memória organizacional.

Perspectivas em Gestão \& Conhecimento, João Pessoa, v. 9, n. 3, p. 4-20, set./dez. 2019. 
A informação não-orgânica está relacionada ao contexto externo organizacional, não há controle, tratamento, segurança e confiabilidade na sua produção, ela é coletada no ambiente externo com o objetivo de subsidiar ações, sem que esteja diretamente associada à organização.

Assim, como o conhecimento do ambiente externo (via informação não-orgânica) é valorizado nos processos de inteligência organizacional, também é fundamental que a organização utilize a informação orgânica encontrada em seus documentos de natureza arquivística: relatórios técnicos, balanços, demonstrativos financeiros, dentre outros documentos produzidos ou recebidos no âmbito da realização de suas funções, geridos e controlados por meio da gestão documental, que "[...] é parte da gestão da informação e pode ser definida como um conjunto de atividades documentais integradas com enfoque na informação arquivística [...]" (VALENTIM, 2012, p. 15), efetuando a Gestão da Informação concreta e duradoura, porém selecionando o que é essencial e de maneira cautelosa, em combinação com as informações não-orgânicas.

Nesse âmbito, a Gestão da Informação é uma importante ferramenta estratégica no ambiente organizacional "[...] a gestão da informação desenvolve atividades que propiciam ao indivíduo acessar dados que estão em bancos, bases, repositórios etc., organizados, tratados e passíveis de recuperação". (VALENTIM; JORGE; CERETTA-SORIA, 2014, p. 220).

Essa definição está em consonância com Choo (2003) ao declarar que a Gestão da Informação é constituída por seis etapas, que as organizações necessitam compreender para realmente fazer uso inteligente dela. As seis etapas compreendem:

- 1a etapa - identificação das necessidades de informação: o conhecimento é derivado de informações estratégicas, de questões problemáticas difíceis, de incertezas e de interpretações ambíguas, embasadas na interação social e experiências experimentadas pelos indivíduos;

- 2a etapa - aquisição da informação: está relacionada a um intenso sistema investigativo que acompanha e avalia diversas fontes como as humanas, textuais, formais e dispostas no ambiente virtual, contemplando tanto o ambiente interno como o externo de maneira sistêmica;

- 3a etapa - organização e armazenamento da informação: as fontes e os sistemas de informação devem dispor de dados e informações organizados que podem ser compartilhados, resgatados ou armazenados no ambiente organizacional;

- 4a etapa - criação de produtos e serviços de informação: está relacionada à capacidade dos indivíduos no acesso, busca, uso e compartilhamento de informações organizacionais;

- 5a etapa - distribuição da informação: está relacionada à utilização de canais para sua disseminação e de meios de comunicação (formais/informais), propiciando continuamente um fluxo de informação no contexto (interno/externo) organizacional e,

- 6a etapa - uso da informação: está relacionada ao significado que os membros organizacionais atribuem à informação, para resultar em geração de conhecimento, em ações e soluções organizacionais.

Por meio da Gestão da Informação, a organização consegue identificar quais são as informações que ela e seus membros necessitam, consegue adquirir, organizar, armazenar, usar, compartilhar e desenvolver novos produtos e serviços, bem como fazer escolhas estratégicas em relação as suas atividades, processos e tarefas. 
A implementação da Gestão da Informação é, portanto, obrigatória em qualquer organização que pretenda melhorar a qualidade da tomada de decisão e ampliar a construção de novos conhecimentos.

\subsubsection{Os fundamentos da Gestão do Conhecimento}

A revolução no contexto organizacional causada pela adoção da Tecnologia da Informação e da Comunicação (TIC), principalmente a partir da década de 1970, alterou profundamente os processos produtivos e as relações de trabalho consolidados durante a Era Industrial e ampliou fortemente a importância do conhecimento nas organizações. Assim como o trabalhador passa a ser visto como indivíduo com toda a sua complexidade: habilidades, competências, sentimentos, dentre outras características que refletem diretamente em seu trabalho, também as organizações se modificam: automatizam-se, profissionalizam-se e iniciam grandes investimentos tecnológicos.

Ao tornar atividades, processos e tomadas de decisões mais dinâmicos, inovadores e velozes, as TICs demonstraram a necessidade do gerenciamento e compilação do conhecimento organizacional. O próprio conceito de conhecimento passou a ser valorizado pelos pesquisadores da Administração. Davenport e Prusak (2003, p. 6) conceituam o conhecimento como:

[...] uma mistura fluída de experiência condensada, valores, informações contextuais e insight experimentado, a qual proporciona uma estrutura para avaliação e incorporação de novas experiências e informações. Ele tem origem e reside na mente dos conhecedores.

O conhecimento é extensão da mente humana, pois se constitui de abstração, das experiências práticas dos indivíduos, das suas ideias, valores, crenças e de toda a sua experiência de vida enquanto ser pensante e reflexivo, que descontrói continuamente suas preconcepções, agregando-lhe valores e um novo significado que o modifica intrinsicamente e gera um novo conhecimento, uma nova compreensão, uma nova ação no ambiente que este está inserido e ao qual pertence.

Nonaka e Takeuchi $(2008$, p. 37) indicam que: "[...] o conhecimento é criado pela síntese do que aparenta ser oposto - isto é, o conhecimento tácito e o explícito. De acordo com o paradigma de administração-conhecimento, somos parte do ambiente e o ambiente é parte de nós". O conhecimento tácito é aquele derivado das experiências, crenças e conhecimento individual de cada um, enquanto o conhecimento explícito é aquele que é registrado formalmente nos procedimentos, atos normativos dentre outros documentos.

Para obter sucesso frente aos seus concorrentes, a organização precisa saber utilizarse do conhecimento tácito dos seus colaboradores gerando a sua formalização por meio do conhecimento explícito. O Modelo SECl (Socialização, Externalização, Combinação e Internalização) compreende os quatros modos de criação de Conhecimento nos indivíduos, elaborados por Nonaka e Takeuchi (2008) no ambiente organizacional, onde:

- Socialização: é o compartilhamento das experiências individuais dos membros organizacionais entre os seus pares, gerando compreensão clara e objetiva, propiciando o conhecimento tácito;

- Externalização: é o compartilhamento individual do conhecimento tácito com o seu grupo, embasado no diálogo e reflexão, gerando conhecimento explícito, com a formalização em documentos;

- Combinação: é o tratamento dado ao seu conhecimento individual, relacionado com o conhecimento explícito e as informações adquiridas e, 
- Internalização: é a aprendizagem adquirida e praticada, utilizando-se do conhecimento tácito prático.

Apropriar-se do Modelo SECl, implementando-o sistematicamente em todos os níveis hierárquicos da empresa (operacional, tático e estratégico) proporcionará às organizações compreender efetivamente o paradoxo problemático que a ambiência organizacional engloba, empregando desse modo, a sua habilidade em ações assertivas quanto ao alinhamento, sensibilização, conscientização, integração e objetividade em todas as extensões desse contexto.

O sucesso das organizações no uso e na aplicação da GC depende da sua postura e dos esforços em relação ao seu papel crítico, ao assumir a responsabilidade com objetividade, de maneira sistêmica e homogênea, convergindo esforços, investimentos, capacidades, recursos, tecnologias, sistemas, informações, cultura, comunicação, dentre outros processos e atividades, em aprendizado contínuo e permanente de todos os seus membros e áreas organizacionais, que resultem constantemente no compartilhamento, criação e agregação de novos conhecimentos.

É importante a implementação da Gestão do Conhecimento (GC) inteligente que gere resultados positivos e satisfatórios e isso se deve à elaboração de projetos concretos, idealizados, reflexivos e que contemplem nove fatores fundamentais descritos por Davenport e Prusak (2003) e que perfazem:

1) Cultura orientada para o conhecimento: está relacionada aos membros organizacionais, dotados de inteligência, curiosidade e desejo de conhecimento, presentes principalmente nos executivos;

2) Infraestrutura técnica e organizacional: está relacionada ao uso da Tecnologia da Informação e da Comunicação (TIC);

3) Apoio da alta gerência: consiste em prover espaços, recursos e infraestruturas para identificação de conhecimentos necessários à organização e aos seus membros, para o processo de aprendizado e de gestão do conhecimento;

4) Vinculação ao valor econômico ou setorial: está vinculado aos benefícios lucrativos que a Gestão do Conhecimento (GC) proporciona à empresa;

5) Alguma orientação para processos: o gestor deve perceber o que satisfaz o seu cliente;

6) Clareza de visão e linguagem: relaciona-se a três fatores essenciais "conhecimento, informação e aprendizado", que englobam desde capacitações, educação continuada entre outros, até as mudanças das diretrizes culturais da empresa;

7) Elementos motivadores não-triviais: estão relacionados a incentivos e motivações duradouras;

8) Algum nível de estrutura do conhecimento: está relacionado à criação de um repositório de conhecimento e,

9) Múltiplos Canais para a transferência de conhecimento: consiste na reunião regular de membros organizacionais dispostos em um ambiente comum, podendo utilizar de sistemas, conferências, web, dentre outros canais.

Ainda, Davenport e Prusak (2003, p. 16) elucidam que a GC está relacionada aos sistemas de informação, às políticas e práticas adotadas pela gestão dos recursos humanos, às mudanças organizacionais necessárias, numa combinação de processos, atividades e recursos. Assim, todas as políticas, práticas e comportamentos de uma empresa emergem de sua cultura organizacional, que é fundamental no desempenho e sucesso do seu segmento e atuação, trabalhando em sincronia com todo o conjunto de elementos que compõem o contexto organizacional.

Perspectivas em Gestão \& Conhecimento, João Pessoa, v. 9, n. 3, p. 4-20, set./dez. 2019. 


\subsection{Os Elementos da Cultura Organizacional}

Ao mesmo tempo em que as TICs ampliavam sua importância na gestão organizacional, uma série de pesquisas sobre o ambiente e a psicologia organizacional culminou na abordagem conhecida como Estudos Organizacionais, ainda na década de 1970, que evoluiu continuamente dando origem a diversas áreas de pesquisa dentre as quais os estudos sobre a Cultura Organizacional.

A dificuldade em definir a Cultura é ampla, como explana Freitas $(2007$, p. 13) ao enfatizar que os antropólogos Kroeber e Kluckholm, em 1952, encontraram 160 diferentes conceitos em seus estudos, mas, foi Linda Smircich em 1983, segundo a autora, que contribuiu de maneira efetiva para a área, trazendo "estudos sobre administração comparativa e o papel das culturas nacionais, à cultura corporativa que tem como implícita a adaptabilidade organizacional, à cognição organizacional que trata dos conhecimentos e aprendizagem compartilhados [...]". No ambiente organizacional, é propício trazer as contribuições de Schein $(2009$, p. 1) ao conceituar cultura nas seguintes palavras:

[...] cultura é um fenômeno dinâmico que nos cerca em todas as horas, sendo constantemente desempenhada e criada por nossas interações com outros e moldada por comportamento de liderança, em um conjunto de estruturas, rotinas, regras e normas.

Fleury e Fischer (1989, p. 117), corroboram ao definir que: "[...] a cultura é concebida como um conjunto de valores e pressupostos básicos expresso em elementos simbólicos, que em sua capacidade de ordenar, atribuir significações, construir a identidade organizacional [...]". A cultura organizacional é extremamente abrangente, envolve pessoas, processos, normas, regras, cognição, percepção, compreensão, sistemas, comunicação, valores, crenças, lembranças, recursos e o próprio ambiente organizacional, servindo como um dos instrumentos direcionadores na concretização das metas, objetivos e resultados.

Assim como Schein (2009) divide a Cultura Organizacioal em três níveis de apreensão, representados pelos artefatos e criações, valores e crenças e pressupostos básicos, Freitas (2007) contribui para a discussão ao indicar um conjunto de sete elementos formadores da Cultura Organizacional, em que esses níveis de apresensão se configuram:

- Valores: estão relacionandos à classificação de escala de importância dada a um determinado conteúdo, informação, sentimento, ação, dentre outros. "Assim, os valores indicam quais são as questões prioritárias a serem observadas, que tipo de informação é mais relevante no processo decisório [...]" (FREITAS, 2007, p. 16);

- Crenças e pressupostos: estão relacionados à percepção individual e coletiva dos membros organizacionais sobre a realidade, incorporada no seu íntimo e transformada em ações. "[...] aquela visão de mundo passa a ser considerada correta e válida, e será recuperada no futuro quando problemas semelhantes ocorrerem" (FREITAS, 2007, p. 18);

- Ritos, rituais e cerimônias: estão relacionados às representações atitudinais e comportamentais intrínsecas que ocorrem de maneira padronizada no ambiente organizacional como: datas comemorativas, aniversários, premiações, reuniões, admissões e aceitação do grupo de trabalho, demissões entre outros. "Os rituais e os ritos são atividades planejadas que manifestam o lado concreto da cultura organizacional" (FREITAS, 2007, p. 19);

- Saga e heróis: representam as narrações e os autores que contemplam o ambiente organizacional, por meio da descrição detalhada e tracejada dos 
caminhos, conflitos, dificuldades, luta, empreendimento, abnegação voltada ao alcance do sucesso, que proporcionaram a vítória e o crescimento frente à concorrência. "Os heróis são parte integrante das sagas e eles também têm funções bem-definidas [...] fornecem um modelo de comportamento [...] exercem influência duradoura que motiva os empregados" (FREITAS, 2007, p. 22);

- Estórias: representam os exemplos sólidos, de viés controlador, que determinam as regras e exceções que o grupo deve seguir e adotar em suas ações. "As estórias são narrativas baseadas em eventos reais que informam sobre a organização, reforçam o comportamento existente e enfatizam como esse comportamento se ajusta ao ambiente organizacional desejado". (FREITAS, 2007, p. 23). Neste sentido, a autora ressalta que também engloba a memória dos indivíduos organizacionais, que podem estabelecer a relação entre o momento presente e o passado, comparando positiviamente ou negativamente todos os comportamentos, eventos, atitudes, mudanças e promessas realizadas no contexto empresarial;

- Tabus: representam toda a forma negativa de comportamento, atitude, ações, decisões, que são consideradas permissivas, obscuras, e proibidas. "[...] os temas relacionados a ele deverão ser esquecidos ou tacitamente evitados. Assim, [...] o grupo passa a considerar como invasão, impertinência, deslealdade ou ofensa grave qualquer menção a esse passado" (FREITAS, 2007, p. 28) e,

- Normas: representam as regras impostas pela empresa que determinam o comportamento dos seus membros organizacionais. "Elas dizem respeito aos procedimentos ou comportamentos considerados o padrão, a regra, para maior parte das situações e eventos organizacionais" (FREITAS, 2007, p. 29).

Esses elementos estão presentes na cultura organizacional, tenham os gestores consciência ou não de cada um deles e de sua influência no organismo corporativo. Para que a empresa consiga gerenciar todos esses aspectos relacionados à cultura organizacional é necessário que além de ferramentas de GI e GC, ela também disponha de profissionais competentes em informação, pró-ativos, capacitados e que saibam manusear, usar e tratar da informação adequadamente, fornecendo aos usuários das diferentes áreas organizacionais, informações, claras, objetivas, assertivas e estratégicas; gerando um planejamento correto, holístico, inovador, consolidado e confiável na construção contínua de informações, conhecimento e da própria cultura organizacional.

\subsection{Os requisitos da Competência em Informação}

A Cultura Organizacional é responsável por propiciar aos seus colaboradores o contexto adequado para fomentar e desenvolver a Colnfo em seus profissionais, resultando em benefícios imensuráveis como: agilidade, qualidade, inovação, apropriação de conhecimento, eliminação de desperdícios, maior segurança em suas tomadas de decisões e competitividade. Trata-se de conceito mais recente, apresentado em 1989 pela American Library Association (ALA) utilizado na época como "Alfabetizado em Informação", elaborado com o auxílio de educadores e bibliotecários, indica que: "[...] para ser alfabetizada em informação, uma pessoa deve ser capaz de reconhecer quando uma informação é necessária e deve ter a habilidade de localizar, avaliar e usar efetivamente a informação [...]" (ALA, 1989, p. 1 , tradução nossa). 
Fortemente relacionado ao desenvolvimento das TICs, esse novo conceito demonstrava que na Era da Informação, uma nova competência deveria se desenvolver: a Competência em Informação (Coinfo), como passou a ser conhecida posteriormente. Ela "[...] inegavelmente, está ligada ao aprendizado e à capacidade de criar significado a partir da informação, sendo uma condição indispensável que as pessoas saibam "aprender a aprender" e realizem o "aprendizado ao longo da vida" (BELLUZZO; KOBAYASHI; FERES, 2004, p. 87).

Além das várias terminologias utilizadas por diferentes autores nacionais e internacionais, realizaram-se também vários encontros e seminários que deram origem a declarações e manifestos que contribuíram para que a Colnfo fosse cada vez mais divulgada, seus estudos compartilhados e a sigla se consolidasse (BELLUZZO, 2014, p. 57).

Para nossa análise, utilizaremos três requisitos descritos por Belluzzo (2013, p. 68-69) e são:

1) Competência em Informação para a cidadania: caracteriza-se pelo comprometimento atuante da sociedade, e das políticas internas e externas, nas diversas esferas municipais, estaduais e federais para o livre acesso dos dados e informações almejando o desenvolvimento dos envolvidos de maneira crítica e transformadora;

2) Competência em Informação para o crescimento econômico: representa a base para qualquer empresa que busque o desenvolvimento em ambientes de negócios, pois utiliza-se com intensidade de conhecimentos passados, presente e futuros de maneira criativa, combinando e gerando serviços de informação efetivos e,

3) Competência em Informação para a empregabilidade: está relacionada à educação, como base estratégica para o desenvolvimento das capacidades, habilidades e conhecimentos dos indivíduos no emprego de sua formação para o sucesso na efetivação de oportunidades.

No ambiente organizacional, além da Colnfo proporcionar todos esses fatores benéficos aos indivíduos e à sociedade, é necessário que o profissional competente em informação "[...] adquira habilidades relacionadas com a busca de novos conhecimentos, aprenda com sua experiência, analise e construa documentos que atendam à necessidade de explicitação do conhecimento" (OTTONICAR; CONDUTA, VITORIANO, 2016, p. 122). Logo, a organização deverá dispor de uma visão ampla sobre a aprendizagem organizacional para que seus membros obtenham a oportunidade de desenvolverem a Colnfo, seja individualmente ou coletivamente.

Esses profissionais competentes em informação acessam a informação adequada que necessitam no ambiente empresarial de maneira efetiva para solucionar os problemas diários, detêm conhecimentos das informações. "Ressalta-se que na organização o documento em si como objeto não é o foco principal da memória organizacional, o mais importante é o conteúdo que ele apresenta" (OTTONICAR; CONDUTA, VITORIANO, 2016, p. 122, grifo nosso). Conseguem ainda selecionar, reter, descartar, tratar e compartilhar a informação necessária, gerando e criando conhecimentos fundamentais para o desempenho empresarial.

Dispondo dessa visão, esse profissional competente em informação é "[...] capaz de tomar decisões lógicas, racionais e flexíveis, que consegue avaliar, comparar, refletir, compreender e visualizar as várias implicações positivas e negativas e seus impactos projetados em ações presentes e futuras" (YAFUSHI, 2015, p. 123).

Assim, ser competente em informação, não é apenas demonstrar capacidade na execução, a competência em informação desse profissional, perfaz também, o emprego de sua habilidade e conhecimento na identificação, representação, compilação de informações essenciais dispostos nos conteúdos desses documentos. A Memória Organizacional pressupõe a competência em informação tanto para produtores da informação quanto para seus usuários. Trata-se de incorporar um ciclo de realimentação, baseado na capacidade individual e coletiva de utilizar adequadamente a informação e o conhecimento.

Perspectivas em Gestão \& Conhecimento, João Pessoa, v. 9, n. 3, p. 4-20, set./dez. 2019. 


\section{ANÁLISE DE RESULTADOS}

O presente trabalho discorreu sobre os temas Gestão da Informação (GI), Gestão do Conhecimento (GC), Cultura Organizacional, Competência em Informação (Colnfo) e Memória organizacional (MO), buscando responder à questão proposta no início da pesquisa: De que maneira o quarteto estratégico influencia a construção e o uso competente da Memória Organizacional?

Apresentaram-se argumentos teóricos embasados em autores reconhecidos e confiáveis da área e por meio dessa consolidação, foi possível elaborar um quadro teóricoconceitual, que segue abaixo, almejando contemplar a colaboração do quarteto estratégico (GI, GC, Cultura Organizacional e Colnfo), para a criação de diretrizes que permitam a reflexão, a criação e uso competente da memória organizacional nos ambientes corporativos/negócios, contemplando cinco focos de atuação.

Quadro 1 - O Quarteto estratégico para a criação e uso competente da Memória Organizacional

\begin{tabular}{|c|c|c|c|c|c|c|}
\hline Item & Focos & $\begin{array}{c}\text { Gestão da } \\
\text { Informação (GI) }\end{array}$ & $\begin{array}{c}\text { Gestão do } \\
\text { Conhecimento (GC) }\end{array}$ & $\begin{array}{l}\text { Cultura Organizacional } \\
\text { (CO) }\end{array}$ & $\begin{array}{l}\text { Competência em } \\
\text { Informação } \\
\text { (Colnfo) }\end{array}$ & $\begin{array}{c}\text { Diretrizes para a } \\
\text { Memória } \\
\text { organizacional }\end{array}$ \\
\hline 1 & $\begin{array}{l}\text { Identificação de } \\
\text { necessidades de } \\
\text { informação / } \\
\text { seleção de } \\
\text { fontes / } \\
\text { Planejamento }\end{array}$ & $\begin{array}{l}\text { Necessidade, } \\
\text { Aquisição e Uso } \\
\text { da Informação }\end{array}$ & $\begin{array}{c}\text { Cultura orientada } \\
\text { para o } \\
\text { conhecimento } \\
\text { Capacidade de } \\
\text { construir, manter, } \\
\text { selecionar e } \\
\text { descartar } \\
\text { conhecimento - } \\
\text { separar o que é útil } \\
\text { do inútil para o seu } \\
\text { conhecimento. }\end{array}$ & $\begin{array}{l}\text { Valores: grau de } \\
\text { importância da } \\
\text { informação } \\
\text { representado no } \\
\text { conteúdo e nas ações }\end{array}$ & $\begin{array}{l}\text { Padrão 1: A pessoa } \\
\text { competente em } \\
\text { informação } \\
\text { determina a } \\
\text { natureza e a } \\
\text { extensão da } \\
\text { necessidade de } \\
\text { informação, } \\
\text { definindo e } \\
\text { reconhecendo a } \\
\text { necessidade de } \\
\text { informação } \\
\end{array}$ & $\begin{array}{l}\text { Investigar os } \\
\text { processos elegíveis } \\
\text { para compor a MO e } \\
\text { selecionar os } \\
\text { indivíduos da } \\
\text { organização, com } \\
\text { maior ativo de } \\
\text { experiência. }\end{array}$ \\
\hline 2 & $\begin{array}{l}\text { Comportamento } \\
\text { / Motivação }\end{array}$ & $\begin{array}{l}\text { Comportamento } \\
\text { adaptativo: } \\
\text { capacidade de } \\
\text { avaliar, dar um } \\
\text { novo significado } \\
\text { à informação, } \\
\text { com base no } \\
\text { seu contexto, } \\
\text { retroalimentar o } \\
\text { processo. }\end{array}$ & $\begin{array}{c}\text { Apoio da Alta } \\
\text { gerência; } \\
\text { Elementos } \\
\text { motivadores não } \\
\text { triviais; } \\
\text { Relacionamento } \\
\text { ativo: capacidade } \\
\text { dos indivíduos em } \\
\text { criar soluções } \\
\text { inovadoras com foco } \\
\text { nos clientes } \\
\end{array}$ & $\begin{array}{l}\text { Crenças e } \\
\text { Pressupostos: envolve a } \\
\text { percepção individual e } \\
\text { coletiva dos sujeitos } \\
\text { organizacionais frente à } \\
\text { realidade aprendida, } \\
\text { incorporada e colocada } \\
\text { em prática }\end{array}$ & $\begin{array}{l}\text { Padrão 2: A pessoa } \\
\text { competente em } \\
\text { informação acessa } \\
\text { a informação } \\
\text { necessária com } \\
\text { efetividade }\end{array}$ & $\begin{array}{c}\text { Criar um ambiente e } \\
\text { cultura } \\
\text { organizacional de } \\
\text { aprendizagem e } \\
\text { compartilhamento do } \\
\text { conhecimento, com o } \\
\text { apoio incondicional } \\
\text { do nível estratégico e } \\
\text { de Recursos } \\
\text { Humanos. }\end{array}$ \\
\hline 3 & $\begin{array}{l}\text { Explicitação e } \\
\text { organização do } \\
\text { conhecimento }\end{array}$ & $\begin{array}{c}\text { Organização e } \\
\text { armazenamento }\end{array}$ & $\begin{array}{c}\text { Infraestrutura } \\
\text { técnica e gerencial; } \\
\text { Estrutura de } \\
\text { conhecimento; } \\
\text { Orientação para } \\
\text { processos. }\end{array}$ & $\begin{array}{c}\text { Ritos, rituais e } \\
\text { cerimônias: } \\
\text { representam as } \\
\text { atitudes e } \\
\text { comportamentos dos } \\
\text { membros } \\
\text { organizacionais, } \\
\text { interiorizadas pela } \\
\text { rotina e explicitada no } \\
\text { ambiente } \\
\text { organizacional; } \\
\text { Estórias: caracterizadas } \\
\text { pelos exemplos } \\
\text { individual e coletivo } \\
\text { dos membros } \\
\text { norteador de } \\
\text { comportamento } \\
\text { organizacional. }\end{array}$ & $\begin{array}{l}\text { Padrão 3: a pessoa } \\
\text { competente em } \\
\text { informação avalia } \\
\text { criticamente a } \\
\text { informação e as } \\
\text { suas fontes, } \\
\text { demonstrando } \\
\text { conhecimento da } \\
\text { maior parte das } \\
\text { ideias contidas nas } \\
\text { informações } \\
\text { necessárias }\end{array}$ & $\begin{array}{c}\text { Organizar a } \\
\text { informação e } \\
\text { formalizar o } \\
\text { conhecimento }\end{array}$ \\
\hline
\end{tabular}

Perspectivas em Gestão \& Conhecimento, João Pessoa, v. 9, n. 3, p. 4-20, set./dez. 2019. 


\begin{tabular}{|c|c|c|c|c|c|c|}
\hline 4 & $\begin{array}{l}\text { Objetivos / } \\
\text { Resultados }\end{array}$ & $\begin{array}{l}\text { Produtos e } \\
\text { serviços de } \\
\text { informação }\end{array}$ & $\begin{array}{l}\text { Vinculação ao valor } \\
\text { econômico ou } \\
\text { setorial } \\
\text { Contribuição } \\
\text { Profissional; } \\
\text { Clareza de visão e } \\
\text { linguagem; } \\
\text { Aprendizagem } \\
\text { transformadora }\end{array}$ & $\begin{array}{l}\text { Saga e heróis } \\
\text { representam os autores } \\
\text { e os caminhos } \\
\text { percorridos que } \\
\text { resultaram em sucesso, } \\
\text { estabelecendo relação } \\
\text { dos acontecimentos } \\
\text { práticos e resultados } \\
\text { efetivos. }\end{array}$ & $\begin{array}{l}\text { Padrão 4: A pessoa } \\
\text { competente em } \\
\text { informação, } \\
\text { individualmente ou } \\
\text { como membro do } \\
\text { grupo usa a } \\
\text { informação com } \\
\text { efetividade para } \\
\text { alcançar um } \\
\text { objetivo / obter } \\
\text { resultados. }\end{array}$ & $\begin{array}{l}\text { Definir produtos e } \\
\text { usos para a memória } \\
\text { organizacional, de } \\
\text { acordo com os } \\
\text { objetivos } \\
\text { organizacionais }\end{array}$ \\
\hline 5 & $\begin{array}{c}\text { Acesso e } \\
\text { realimentação }\end{array}$ & $\begin{array}{l}\text { Distribuição da } \\
\text { Informação }\end{array}$ & $\begin{array}{l}\text { Múltiplos canais de } \\
\text { transferência de } \\
\text { Conhecimento; } \\
\text { Capacidade de } \\
\text { avaliar o } \\
\text { conhecimento } \\
\text { criado }\end{array}$ & $\begin{array}{l}\text { Normas: as regras } \\
\text { estabelecidas são } \\
\text { respeitadas pelos } \\
\text { indivíduos por meio de } \\
\text { seu comportamento no } \\
\text { cumprimento do que } \\
\text { Ihe foi determinado }\end{array}$ & $\begin{array}{l}\text { Padrão } 5 \text { - a pessoa } \\
\text { competente em } \\
\text { informação } \\
\text { compreende as } \\
\text { questões } \\
\text { econômicas, legais } \\
\text { e sociais da } \\
\text { ambiência, do uso } \\
\text { da informação e } \\
\text { acessa e usa a } \\
\text { informação ética e } \\
\text { legalmente. }\end{array}$ & $\begin{array}{c}\text { Elaborar um sistema } \\
\text { de gestão, } \\
\text { contemplando a base } \\
\text { de dados com os } \\
\text { conhecimentos } \\
\text { explicitados, } \\
\text { associada a } \\
\text { ferramentas de } \\
\text { disseminação, e } \\
\text { definir o processo de } \\
\text { realimentação. }\end{array}$ \\
\hline
\end{tabular}

Fonte: Elaborado pelas autoras. Baseado e Adaptado de: Davenport; Prusak (2003); Valentim, Jorge; Soria (2014, p. 222-223); Menezes (2006, p. 37); Soltero (2002, p. 11-13); Belluzzo (2007, p. 95-103) e Freitas (2007, p. 16-29).

No primeiro item, o Quadro 1 aborda como foco a "Identificação de necessidades de informação / seleção de fontes / planejamento" que propicia uma transversalidade entre a GI, GC, Co e Colnfo, na medida que a necessidade de informação e uso da informação estão atrelados à capacidade do indivíduo de construir o conhecimento e mantê-lo, embasada em experiências internalizadas e práticas que constituem a Colnfo, onde o profissional consegue selecionar, descartar e identificar sua necessidade sobre o tipo de informação necessária para a geração de conhecimento diariamente.

O segundo item contemplou como foco o "Comportamento/Motivação" gerando uma transversalidade entre a GI, GC, Co e Colnfo, na medida em que o indivíduo avalia a informação proporcionando um novo significado, se adaptando ao contexto, criando soluções inovadoras voltadas à solução de problemas frente as experiências vivenciadas e aprendidas, resultando na aplicação da Coinfo na medida que os indivíduos acessam a informação necessária de modo efetivo, proporcionando ações práticas para satisfazer seus clientes.

O item três contemplou como foco a "Explicitação e organização do conhecimento" gerando uma transversalidade entre a GI, GC, Co e Colnfo, na medida que o registro do conhecimento e a organização da informação proporciona o armazenamento do conhecimento gerado, seja por meio do comportamento, atitudes ou estórias dos membros organizacionais, que ao compartilharem as informações e o conhecimento de maneira explícita na rotina organizacional como descritas nas normas, políticas, missão e valores da empresa ou outros documentos, poderão ser acessados e disponibilizados em procedimentos ou fontes internas de informação, resultando na aplicação da Colnfo na medida que os indivíduos avaliam criticamente a informação e as suas fontes, demonstrando conhecimento da maior parte das ideias contidas nas informações necessárias.

O item quatro contemplou como foco os "Objetivos/ Resultados" gerando uma transversalidade entre a GI, GC, Co e Colnfo, na medida que a organização propicia um contexto agregador de produtos e serviços de informação, que contribuem para que os membros organizacionais/ profissionais consigam êxito práticos por meio da aplicação da Colnfo individualmente ou como membro do grupo ao usar a informação com efetividade para alcançar um objetivo ou obter resultados. Estes produtos devem privilegiar o maior valor 
agregado para a organização, e apresentar clareza de visão e linguagem de modo a contribuir para a aprendizagem organizacional transformadora.

O item 5 contemplou como foco o "Acesso e realimentação", gerando uma transversalidade entre a GI, GC, CO e Colnfo, na medida em que a organização distribui a informação com base em um contexto adequado para que seus membros organizacionais sejam capazes de avaliar o conhecimento criado, resultado em novo comportamento responsável ou competente em informação, compreendendo as questões econômicas, legais e sociais de seu ambiente, de modo a acessar e utilizar a informação de maneira ética e legal. A avaliação do conhecimento produzido e o registro das mudanças provocadas possibilita a realimentação do ciclo de conhecimento e amplia as possibilidades de utilização.

Neste viés, a partir da análise das Etapas da GI, dos fatores da GC, dos Elementos da CO e dos padrões da Colnfo, sugerem cinco diretrizes que nortearão a implantação da Memória Organizacional, apresentados no quadro a seguir. Os itens foram organizados de acordo com aspectos que permitem correspondência aproximada entre os diversos elementos do quarteto estratégico analisados.

A partir da compreensão de elementos extraídos do Quarteto Estratégico foi possível elaborar cinco diretrizes que auxiliarão na construção e uso eficiente da memória organizacional. Essas diretrizes devem estar de acordo com os objetivos da empresa e ser profundamente discutidas com equipe multidisciplinar, envolvendo vários setores, tais como: Arquivo, Recursos Humanos, Qualidade, Contabilidade, Fiscal, dentre outros que formam a cadeia produtiva da organização. Para melhores resultados, a aplicação das diretrizes deve seguir uma ordem de prioridades, focando em processos mais representativos para a organização, dentro de cada área. A atuação por áreas possibilita a ação direcionada para as características informacionais específicas. Destaca-se a importância de um projeto piloto, uma vez que a memória organizacional abarca e reflete a cultura organizacional da empresa.

A primeira diretriz é investigar os processos elegíveis para compor a memória organizacional e selecionar os indivíduos com maior ativo de experiência. Abarca identificar quais colaboradores são ou foram responsável por mais tempo pelos processos em foco. Porém, é de suma também é importante identificar todos os colaboradores que já passaram pelos processos. A construção e uso da memória organizacional é um trabalho conjunto, trabalhar com todos os envolvidos é fundamental. Com isso, é possível identificar as necessidades de informação e os valores organizacionais envolvidos no processo. Essa diretriz refere-se à identificação das necessidades de informação e à seleção de suas fontes.

A segunda diretriz consiste em criar um ambiente e cultura organizacional de aprendizagem e compartilhamento de conhecimento, com apoio incondicional do nível estratégico e de Recursos Humanos, que refletirá no sucesso ou fracasso do projeto. Explicitar o conhecimento em ambientes que não possuem cultura de aprendizagem pode causar nos envolvidos sentimentos de insegurança, de substituição, dentre outros que atrapalharão o andamento da construção da memória organizacional. Logo, é necessário explanar e informar claramente os colaboradores sobre os objetivos da Memória Organizacional.

Organizar a informação e formalizar o conhecimento: a terceira diretriz, sem dúvidas, é uma premissa da Memória Organizacional. Com isso e por meio de métodos e técnicas adequadas será possível registrar o conhecimento do colaborador, para isso, utilizar-se-á de ferramentas de gestão da informação e do conhecimento, como bancos de dados, fluxogramas, manuais de procedimentos, dentre outros. Essas ferramentas associam a informação registrada (com foco principal na informação orgânica) e no registro do conhecimento tácito), de modo a que possam ser reutilizados posteriormente. Esses instrumentos deverão ser construídos em conjunto com todos os envolvidos, desde o colaborador mais antigo que teve contato com o processo, até o atual responsável.

Perspectivas em Gestão \& Conhecimento, João Pessoa, v. 9, n. 3, p. 4-20, set./dez. 2019. 
A quarta diretriz, definir produtos e usos para a Memória Organizacional, de acordo com os objetivos organizacionais, está relacionada ao estabelecimento claro dos usos destinados à informação organizada e ao conhecimento registrado no âmbito da Memória Organizacional. Um dos fatores de fracasso da MO pode ser a inexistência de uso concreto para o conteúdo preservado. As ações relacionadas a essa diretriz devem complementar as ações desenvolvidas a partir da primeira diretriz. Com base nas necessidades e fontes de informação, é possível identificar possíveis usos. Essa diretriz está relacionada aos objetivos e resultados esperados com a implantação da Memória Organizacional.

A quinta e última diretriz elaborar um sistema de gestão, contemplando a base de dados com os conhecimentos explicitados, associada a ferramentas de disseminação e processo de realimentação, relaciona-se diretamente com a terceira, pois sugere-se que a formalização do conhecimento seja realizada por meio de ferramentas que facilitam o acesso ao conhecimento explicitado. Ressalta-se a importância de criar níveis de acesso, para que somente pessoas autorizadas possam acessá-los.

A elaboração do Quadro 01- Quarteto estratégico para a criação e uso competente da Memória Organizacional permitiu visualizar as interfaces contributivas do Quarteto Estratégico para a Memória Organizacional, de tal modo que possibilitou a construção das diretrizes aqui expostas. A complexidade de um projeto de Memória Organizacional abarca desde a cultura da organização, até mesmo seu uso, por isso as diretrizes aqui expostas, buscaram criar meios para minimizar esses impactos e contribuir com o sucesso do projeto.

\section{CONSIDERAÇÕES FINAIS}

O quadro teórico-conceitual apresentado busca proporcionar a compreensão das diretrizes fundamentais que nortearão as atividades organizacionais para alcance de diferencias estratégicos, que subsidiarão a criação e uso competente da Memória Organizacional (MO).

Dessa maneira, entende-se que a Gestão da Informação (GI), Gestão do Conhecimento (GC), a Cultura Organizacional e a Competência em Informação (Colnfo) são ferramentas de sustento, agregadoras no apoio da construção e uso competente da Memória Organizacional, pois quando implementadas e utilizadas nos ambientes organizacionais geram o domínio efetivo de ferramentas tecnológicas, de sistemas e fluxos de informação; bem como, da socialização, distribuição, transferência, compartilhamento, mapeamento e construção de conhecimento.

Neste aspecto, o Quarteto Estratégico influencia a criação e o uso competente da Memória Organizacional, uma vez que estes são ferramentas estratégicas que dispõem de informações que foram identificadas, reconhecidas, analisadas, selecionadas, descartadas, compreendidas, compiladas, tratadas e processadas, resultando em um comportamento organizacional equilibrado, com redução de conflitos e confiável.

Isso tudo reflete na flexibilidade diante de novos problemas, possibilitando um gerenciamento assertivo de informações e conhecimento e propiciando insights para novos produtos, novos serviços, consolidação, valorização e reconhecimento da imagem e da marca, fidelização de clientes e interesse de investidores. Todos os elementos elencados formam a base para a implantação e utilização da Memória Organizacional, proporcionando o registro do conhecimento, trajetória, inovação, transformação dos processos, dentre outros elementos, que resultarão em tomadas de decisões e ações assertivas e estratégicas na geração de sucesso no contexto organizacional.

Perspectivas em Gestão \& Conhecimento, João Pessoa, v. 9, n. 3, p. 4-20, set./dez. 2019. 


\section{REFERÊNCIAS}

AMERICAN LIBRARY ASSOCIATION. A progress report on information literacy: an update on the American Library Association Presential Committee on Information Literacy: Final Report. 1989.

ARRUDA, M. F. de. Cultura Organizacional e Inovação: estudo de caso em um hospital privado com características de inovação no município de São Paulo. 2006. Dissertação (Mestrado) Escola de Administração de Empresas de São Paulo da Fundação Getúlio Vargas, FGV, São Paulo, 2006.

BELLUZZO, R. C. B. O conhecimento, as redes e a competência em informação (Colnfo) na sociedade contemporânea: uma proposta de articulação conceitual. Perspectivas em Gestão \& Conhecimento, João Pessoa, v. 4, Número Especial, p. 48-63, out. 2014.

BELLUZZO, R. C. B. Competência em informação: vivências e aprendizado. In: BELLUZZO; R. C. B., FERES, G. G. (Orgs.). Competência em informação: de reflexões às lições aprendidas. São Paulo: FEBAB, 2013. p. 65-80.

BELLUZZO, R. C. B. Construção de mapas: desenvolvendo competências em informação e comunicação. 2. ed. Bauru: Cá Entre Nós, 2007.

BELLUZZO, R. C. B.; KOBAYASHI, M. C. M.; FERES, G. G. Information literacy: um indicador de competência para a formação permanente de professores na sociedade do conhecimento. ETD - Educação Temática Digital, Campinas, v. 6, n. 1, p. 81-99, dez. 2004.

BIGHETTI, W. V. F. Memória organizacional como estratégia de comunicação: um estudo sob o viés da recepção do público jovem. Dissertação (Mestrado) - Universidade Estadual Paulista. Faculdade de Artes, Arquitetura e Comunicação, Bauru, 2016. 187f. Disponível em: http://repositorio.unesp.br/bitstream/handle/11449/144234/bighetti wvf me bauru.pdf?seq uence $=7$. Acesso em: 30 nov. 2016.

CHOO, C. W. A organização do conhecimento: como as organizações usam a informação para criar significado, construir conhecimento e tomar decisões. São Paulo: Senac, 2003.

DAVENPORT, T. H.; PRUSAK, L. Projetos de gestão do conhecimento na pratica. In: Conhecimento empresarial: como as organizações gerenciam o seu capital intelectual. Rio de Janeiro: Elsevier, 2003.

FLEURY, M. T.; FISCHER, R. M. Cultura e poder nas organizações. São Paulo: Atlas, 1989.

FREITAS, M. E. Cultura organizacional e seus elementos. In: Cultura organizacional: evolução e crítica. São Paulo: Cengage Learning, 2007. p. 11-30.

KROEBER, A. L., KLUCKHOHN, C. Culture: a critical review of concepts and definitions. Cambridge: Peabody Museum, n. 1, v. 47, 1952.

LE GOFF, J. Memória. In: História e memória. Campinas: Editora da Unicamp, 1992, P. 423-483.

Perspectivas em Gestão \& Conhecimento, João Pessoa, v. 9, n. 3, p. 4-20, set./dez. 2019. 
LOUSADA, M. Informação orgânica como insumo estratégico para a tomada de decisão em ambientes competitivos. Dissertação (Mestrado em Ciência da Informação) - Faculdade de Filosofia e Ciências, Universidade Estadual Paulista. Marília, 2011. 250 f. Disponível em: https://www.marilia.une sp.br /Home/PosGraduacao/Cienciadalnformacao/Dissertacoes/lousada $m$ me mar.pdf. Acesso em: 30 nov. 2016.

MARCONI, M. A.; LAKATOS, E. M. Técnicas de pesquisa: planejamento e execução de pesquisas, amostragens e técnicas de pesquisa, elaboração, análise e interpretação dos dados. São Paulo: Atlas, 2006.

MENEZES, E.M.de. Estruturação da memória organizacional de uma instituição na iminência de evasão de especialistas: um estudo de caso na Cohab. Brasília: PPGGCTI/Universidade Católica de Brasília, 2006. Disponível em https://bdtd.ucb.br:8443/jspui/bitstream/123456789/1476/1/Texto\%20Completo.pdf.

MOLINA, L. G.; VALENTIM, M. L. P. Memória organizacional: proposta de um modelo para implantação em instituições. Revista Ibero-Americana de Ciência da Informação, v. 7, n. 2, 2015.

NONAKA, I; TAKEUCHI, H. Gestão do conhecimento. Porto Alegre: Bookman, 2008.

OTTONICAR, S.L. C; CONDUTTA, L.F.; VITORIANO, MC.C.P.. Competência em Informação e Cultura Organizacional: fatores fundamentais na construção da memória organizacional. InCID: Revista de Ciência da Informação e Documentação, Ribeirão Preto, v. 7, n. 1, p. 111-130, abr. 2016.

ROUSSEAU, J.Y; COUTURE, C. O lugar da Arquivística na Gestão da Informação. In: Os Fundamentos da Disciplina Arquivística. Lisboa: Publicações Dom Quixote, 1998. p.61-76

SANTOS, V. C. B. Competência em informação na construção da inteligência competitiva nas organizações: o caso da empresa Mizumo. 177f. 2014. Dissertação (Mestrado em Ciência da Informação) - Universidade Estadual Paulista, Faculdade de Filosofia e Ciências - UNESP, Marília, 2014.

SCHEIN, E. Cultura Organizacional e Liderança. São Paulo: Atlas, 2009.

SMIRCICH, L. Concepts of Culture and Organizational analysis. In: Administrative Science Quartely, n. 28, pp. 339-358, 1983.

SOLTERO, A. P. Memória organizacional baseada em casos. Revista de Ciência e Tecnologia, Recife, v.6, n.1, p.22-39, 2002.

VALENTIM, M. L. Pomim; JORGE, C. F. B; SORIA, M. G. C. Contribuição da competência em informação para os processos de gestão da informação e do conhecimento. Em Questão, p. 207-231, 2014.

VALENTIM, Marta Ligia Pomim (org.). Gestão documental em ambientes empresariais. In: Estudos Avançados em Arquivologia. Marília: Oficina universitária: São Paulo: Cultura Acadêmica, 2012. 
YAFUSHI, C. A. P. A Competência em informação para a construção de conhecimento no processo decisório: estudo de caso na Duratex de Agudos (SP). 229f. 2015. Dissertação (Mestrado em Ciência da Informação) - Universidade Estadual Paulista, Faculdade de Filosofia e Ciências - UNESP, Marília, 2015. 